\title{
El agua en América Latina
}

J Selva Andina Biosph. 2016; 4(2):46-47.

El uso racional del agua en la actualidad constituye en uno de los mayores retos de la humanidad. En este sentido, el agua en América Latina llega a ser uno de los recursos esenciales para toda forma de vida. Según cálculos del Programa Ambiental de Naciones Unidas, la región cuenta con el 65\% de agua dulce del mundo. Sin embargo, la relación entre la oferta y demanda de agua da lugar a situaciones muy complejas y distintas, dependiendo de cada país.

La frecuente escasez del agua en la Región Andina, ocasionada por el cambio climático, las sequías prolongadas y, el aumento constante de la población humana, ocasionan, conflictos entre regiones, por el control y uso del agua. Por otra parte el $97.5 \%$ del agua existente en el planeta es salada, mientras que un $2.5 \%$ del recurso hídrico es apto para el consumo de los seres humanos y para el desarrollo de las actividades agropecuarias, sugiriendo el mejor aprovechamiento, para reducir los conflictos sociales derivados de los monopolios que controlan el recurso hídrico.

Este hecho tendrá repercusiones económicas y geopolíticas en todo el mundo, aunque en América se verá involucrada por el contraste manifiesto que existe entre la zona septentrional, cada vez más sedienta y esquilmada de sus recursos hídricos, y el área meridional, donde el agua es abundante y todavía no ha sido debidamente aprovechada.

En cualquier caso, se puede hablar con absoluta propiedad de la existencia de una disputa del agua entre el centro y la periferia, entre grupos antagónicos con intereses contrapuestos donde una vez más se generan desequilibrios y exclusiones socioeconómicas, culturales, políticas y ambientales. Se establece de hecho una pugna entre quienes piensan que el agua debe ser considerada un bien comercial y quienes sostienen que se trata de un bien social relacionado con el derecho a la vida.

Ante ésta realidad se hace indispensable seguir trabajando en la conservación de los páramos Andinos, manteniendo su biodiversidad, que garanticen la cantidad y calidad del agua, considerando a éste ecosistema natural una fuente hídrica invaluable para la vida en el planeta.

Se requiere trabajar mancomunadamente con instituciones gubernamentales y no gubernamentales que mejoren 


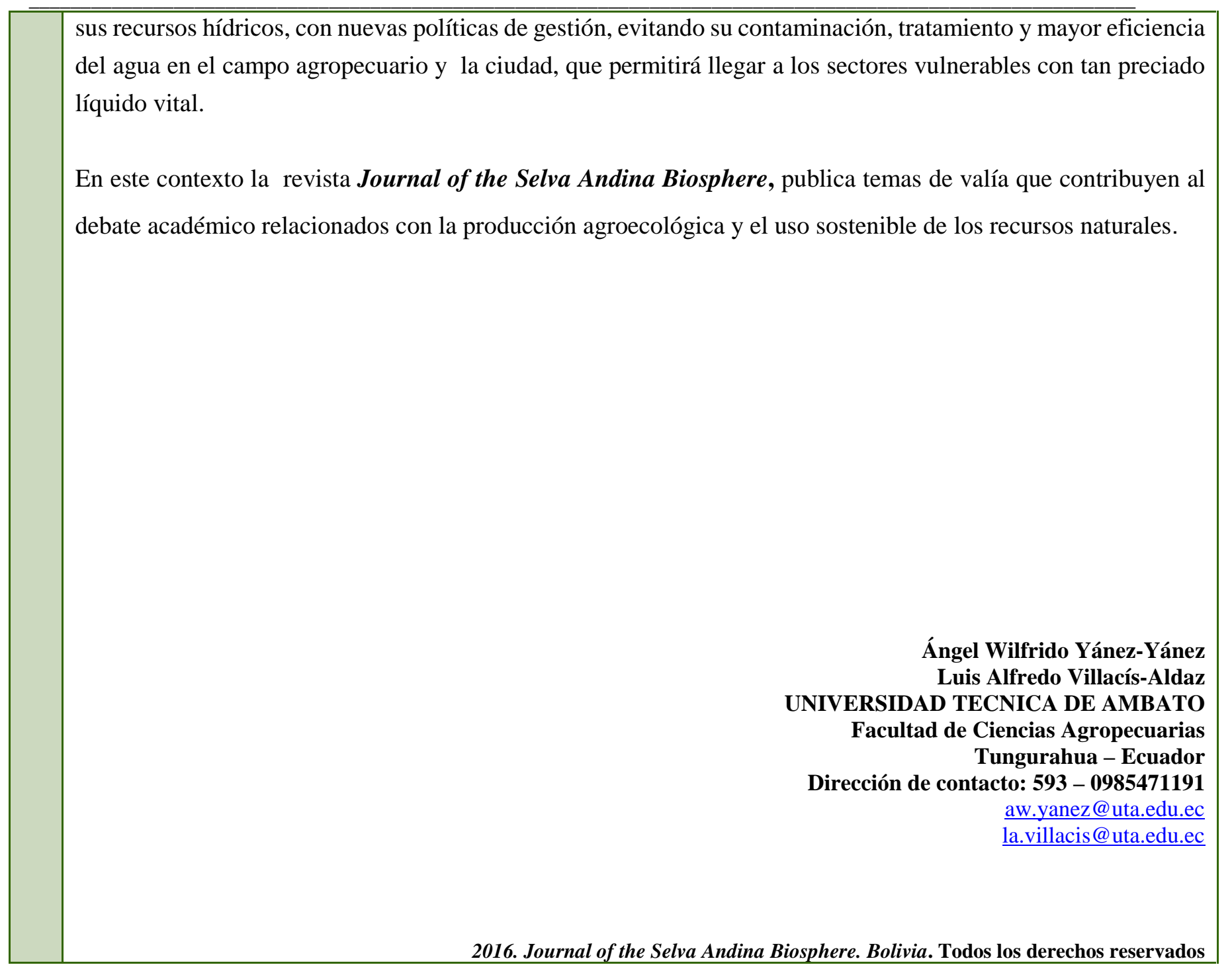

